\title{
REVIEW
}

\section{Myorelaxants in ARDS patients}

\author{
Sami Hraiech ${ }^{1,2}$, Takeshi Yoshida ${ }^{3}$, Djillali Annane ${ }^{4}$, Abhijit Duggal ${ }^{5}$, Vito Fanelli ${ }^{6}$, Arnaud Gacouin ${ }^{7}$, Leo Heunks ${ }^{8}$, \\ Samir Jaber ${ }^{9}$, Peter D. Sottile ${ }^{10}$ and Laurent Papazian ${ }^{1,2^{*}}$ (D)
}

(c) 2020 Springer-Verlag GmbH Germany, part of Springer Nature

\begin{abstract}
Neuromuscular blocking agents (NMBAs) inhibit patient-initiated active breath and the risk of high tidal volumes and consequent high transpulmonary pressure swings, and minimize patient/ ventilator asynchrony in acute respiratory distress syndrome (ARDS). Minimization of volutrauma and ventilator-induced lung injury (VILI) results in a lower incidence of barotrauma, improved oxygenation and a decrease in circulating proinflammatory markers. Recent randomized clinical trials did not reveal harmful muscular effects during a short course of NMBAs. The use of NMBAs should be considered during the early phase of severe ARDS for patients to facilitate lung protective ventilation or prone positioning only after optimising mechanical ventilation and sedation. The use of NMBAs should be integrated in a global strategy including the reduction of tidal volume, the rational use of PEEP, prone positioning and the use of a ventilatory mode allowing spontaneous ventilation as soon as possible. Partial neuromuscular blockade should be evaluated in future trials.
\end{abstract}

Keywords: Muscle relaxants, Protective ventilation, Prone positioning, Corticosteroids, ECMO, Sedation, PEEP

\section{Introduction}

Mechanical ventilation (MV) is the basis of the treatment of patients presenting with acute respiratory distress syndrome (ARDS). The respective roles of mechanical ventilation with preserved spontaneous breathing (SB) and completely controlled mechanical ventilation using neuromuscular blocking agents (NMBAs) need to be clarified at the very early phase of ARDS. However, these two seemingly opposing strategies should be complementary, and defining the appropriate timing using these two strategies successively is warranted.

The current SARS-CoV-2 pandemic is associated with NMBA shortage in different countries, suggesting their widespread use [1]. Even before the publication of specific studies regarding the use of NMBAs in ARDS patients, their use was not trivial. In a sub-study of the

\footnotetext{
*Correspondence: laurent.papazian@ap-hm.fr

${ }^{1}$ Assistance Publique - Hôpitaux de Marseille, Hôpital Nord, Médecine Intensive Réanimation, 13015 Marseille, France
}

Full author information is available at the end of the article
ALVEOLI trial comparing a high PEEP strategy to a low PEEP strategy, continuous NMBAs were used at baseline in $30 \%$ and $25.4 \%$ of the lower and higher PEEP groups, respectively, and in $45 \%$ and $33 \%$ of patients with lower and higher PEEP between day 0 and day 28 [2]. Factors that were found to be associated with NMBA use are mainly related to disease severity, as assessed by a high APACHE III score, a large alveolar-arterial oxygen gradient, and a high plateau pressure [2]. Moreover, the use of prone positioning [3], permissive hypercapnia to ensure protective ventilation, extra-corporeal membrane oxygenation (ECMO) [4] or high-frequency oscillatory ventilation may require the use of NMBAs [5]. The purpose of this narrative review is to present an updated discussion on the role of muscle paralysis during mechanical ventilation in ARDS patients, based both on pathophysiological concepts and data obtained from clinical studies.

\section{实




\section{Pharmacology of NMBAs}

Physiologically, acetylcholine $(\mathrm{ACh})$ is released from the presynaptic motor nerve terminus, diffuses across the synaptic cleft, and binds to ligand-gated nicotinic acetylcholine receptors (AChRs) on the postsynaptic motor endplate. The binding of ACh increases the membrane permeability, which decreases the transmembrane potential. When the threshold potential is reached, the action potential is propagated, resulting in skeletal muscle cell contraction. The action of $\mathrm{ACh}$ is rapidly terminated by the enzyme acetylcholinesterase. NMBAs cause skeletal muscle relaxation by blocking the acetylcholine receptor neuromuscular junction [6]. These agents are classified by their mechanism of action and chemical structure. Depolarising NMBAs bind and activate AChRs, whereas non-depolarising NMBAs bind and competitively antagonize AChRs. Succinylcholine is the only depolarising agent but is not used as continuous infusion. The group of non-depolarising NMBAs is further subdivided according to their structure into benzylisoquinoliniume.g., atracurium, cisatracurium and mivacurium, and amino steroidal compounds-e.g., rocuronium, vecuronium and pancuronium. Steroid compounds appear to further favor the occurrence of myopathies because of their structural analogy [7]. Moreover, they are metabolized into active metabolites; the elimination of these metabolites can be disturbed in renal or liver failure, and there is a risk of accumulation, especially if administered for several days. On the contrary, benzylisoquinolines are metabolized to inactive compounds by plasma esterases, depending upon the plasma temperature and $\mathrm{pH}$. There is no risk of a prolonged muscular block after ending the infusion of these agents even in critically ill patients with renal or liver failure [8]. The choice of the adequate non-depolarising NMBA depends on both the indication and patient's comorbidities (e.g., renal and liver failure). Pancuronium was the first amino steroidal compound introduced clinically. It stimulates muscarinic receptors, especially cardiac receptors with an atropine-like effect (vagal blockade with tachycardia). Atracurium and cisatracurium are preferred agents for continuous infusions due to the fact that their metabolism is unrelated to renal or hepatic function. They are both intermediate-acting NMBAs. Atracurium is metabolized through nonspecific plasma esterase-mediated hydrolysis as well as by the Hofmann elimination reaction, which is independent of hepatic and renal function, making this agent an attractive option in the intensive care unit in patients with renal and/or hepatic dysfunction. Cisatracurium is an isomer of atracurium, with a fourfold increased potency and without the associated histamine release. It is metabolized through organ-independent mechanisms via the Hofmann elimination reaction, making this

\section{Take-home message}

The use of NMBAs should be considered during the early phase of severe ARDS for patients who despite deep sedation cannot be ventilated according to lung protective ventilation criteria or patients in prone position only after adjusting mechanical ventilation settings and sedation. The use of NMBAs should be integrated into a global strategy involving low tidal volume, a judicious use of PEEP, prone positioning and the use of a ventilatory mode allowing spontaneous ventilation as soon as possible.

benzylisoquinolinium drug one of the most commonly utilized NMBAs in critically ill patients who require neuromuscular blockade $[9,10]$ Main differences between benzylisoquinoliniums and other NMBAs are reported in Table 1.

Selecting a specific NMBA in the critically ill patient depends on the indication, patient's comorbidities (liver or renal failure), interactions with other drugs, physiological changes and risk factors that may affect the pharmacokinetics of NMBAs, such as age-related changes, hypothermia, sepsis, and metabolic or electrolyte disturbances. Tachyphylaxis has also been documented with NMBAs use, and clinical guidelines recommend that patients who develop tachyphylaxis to one NMBA should try another drug (rather from another class) if neuromuscular blockade is still required [11].

\section{Plausible beneficial effects of NMBAs in ARDS patients}

Several pathophysiological hypotheses have been proposed to explain why NMBAs used during the acute phase of moderate-to-severe ARDS might improve the outcomes. Figure 1 summarizes the key mechanisms. The main effects probably involve the following:

\section{Reduction of patient-to-ventilator asynchronies and better adaptation to protective ventilation}

Better control of the tidal volume by limiting inspiratory efforts and inhibition of active expiration help to decrease baro, volu and atelectrauma [12]. Thus, NMBAs limit the occurrence of high and large swings of transpulmonary pressure related to strong inspiratory efforts, as well as expiratory collapse by inhibiting active expiration. Strong expiratory efforts can generate negative transpulmonary pressure (when pleural pressure is higher than PEEP) and lead to alveolar collapse [13]. By the way, NMBAs could limit derecruitment and allow the maintenance of PEEP [13, 14]. These events are associated with a decrease in lung blood flow and alveolar-capillary permeability. NMBAs also prevent breath stacking, a patient-ventilator interaction in which consecutive machine inspiratory cycles occur in close succession with 
Table 1 Pharmacology of commonly used neuromuscular blocking agents

\begin{tabular}{|c|c|c|c|c|c|}
\hline Agent & $\begin{array}{l}\text { ED95/ } \\
\text { Intubating dose (mg/kg) }\end{array}$ & Onset time (min) & $\begin{array}{l}\text { Infusion } \\
\text { dose } \\
(\mu \mathrm{g} / \mathrm{kg} / \mathrm{min})\end{array}$ & Duration of action & Elimination \\
\hline Succinylcholine & $0.5-0.6 / 1-1.2$ & $0.5-1 \mathrm{~s}$ & NF & $10-12 \mathrm{~min}$ & $\begin{array}{l}\text { Metabolized by plasma } \\
\text { cholinesterase. No active } \\
\text { metabolite }\end{array}$ \\
\hline Rocuronium & $\begin{array}{l}0.3 / 0.6 \\
\text { (1.2 for rapid sequence induc- } \\
\text { tion) }\end{array}$ & $\begin{array}{l}1.5-3 \\
\text { ( } 1 \text { for rapide induction dose) }\end{array}$ & $5-12$ & 20-70 min & $\begin{array}{l}\text { Eliminated by the liver (90\%) } \\
\text { and kidneys (10\%). No active } \\
\text { metabolite }\end{array}$ \\
\hline Pancuronium & $0.07 / 0.1$ & $3-5$ & $0.8-1.7$ & $20-40 \mathrm{~min}$ & $\begin{array}{l}\text { Eliminated by the liver (15\%) } \\
\text { and kidneys ( } 85 \%) \text {. Active } \\
\text { metabolite }=3-\mathrm{OH} \text {-pancuro- } \\
\text { nium, accumulating in case of } \\
\text { renal failure }\end{array}$ \\
\hline Vecuronium & $0.05 / 0.08-0.1$ & $3-5$ & $0.8-1.7$ & $20-40 \mathrm{~min}$ & $\begin{array}{l}\text { Eliminated by the liver (60\%) } \\
\text { and kidneys (40\%). Active } \\
\text { metabolite }=3 \text {-desacetyl- } \\
\text { Vecuronium, accumulating in } \\
\text { case of renal failure }\end{array}$ \\
\hline Cisatracurium & $0.05-0.07 / 0.15$ & $4-7$ & $1-3$ & $35-50 \mathrm{~min}$ & $\begin{array}{l}\text { Hofmann elimination. No active } \\
\text { metabolite }\end{array}$ \\
\hline Atracurium & $0.25 / 0.5$ & $3-5$ & $10-20$ & $30-45 \mathrm{~min}$ & $\begin{array}{l}\text { Metabolized by plasma esterase } \\
\text { and Hofmann elimination. } \\
\text { Metabolite = laudanosine, } \\
\text { possible neurologic toxicity at } \\
\text { high continuous doses) }\end{array}$ \\
\hline Mivacurium & $0.08 / 0.25$ & $2-3$ & $5-6$ & $12-20 \mathrm{~min}$ & $\begin{array}{l}\text { Metabolized by plasma } \\
\text { cholinesterase. No active } \\
\text { metabolite }\end{array}$ \\
\hline
\end{tabular}

ED95 effective dose $95 \%$ : the amount of NMBA required to reduce twitch height by $95 \%$. NF not feasible

incomplete exhalation between them, typically due to inspiratory muscle effort early during the machine expiratory phase. Breath stacking can result in regular exposure to potentially injurious and occult high Vt despite ventilator settings consistent with a lung-protective strategy. By eliminating breath-stacking dyssynchrony, NMBAs ensure provision of the intended low-Vt strategy [15]. Inspiratory efforts can be clinically undetectable or associated with undiagnosed reverse triggering (a breath delivered by the ventilator triggering a contraction of the diaphragm responsible for a spontaneous breath [16]), which can be frequent even under deep sedation in nonparalysed patients [17]. Finally, an elevated rate of asynchronies has been shown to be associated with higher ICU and hospital mortality [18].

Lastly, paralysing ventilatory muscles to allow controlled ventilation could facilitate the tolerance of permissive hypercapnia.

\section{Decrease in oxygen consumption}

NMBAs have been shown to decrease oxygen consumption, mainly by eliminating muscular activity and improving systemic oxygenation, particularly in muscles implicated in respiratory function [19]. Through this mechanism, NMBAs likely reduce respiratory demand and cardiac output, followed by an increase in the mixed venous partial pressure of oxygen and the partial pressure of arterial oxygen. Reducing the work of breathing during mechanical ventilation by neuromuscular paralysis may lower the whole-body oxygen consumption in a significant manner (a 25\% reduction has been reported [20]) and redistribute the blood flow to the splanchnic and other non-vital vascular beds [20]. Sparing oxygen consumption, NMBAs could reduce respiratory demand, contributing to reduce VILI from high minute ventilation and excessive patient effort, whereas decreasing cardiac output may decrease VILI from pulmonary vascular strain [21].

\section{Increased thoraco-pulmonary compliance and functional residual capacity}

This might be associated with a decrease in the intra-pulmonary shunt due to PEEP maintenance and lower atelectasis in dependant regions of the lungs [22]. NMBAs improve the mechanical viscoelastic properties of the chest wall. An improved ventilation-perfusion ratio may also be related to a more uniform distribution of lung perfusion due to the application of lower pulmonary 


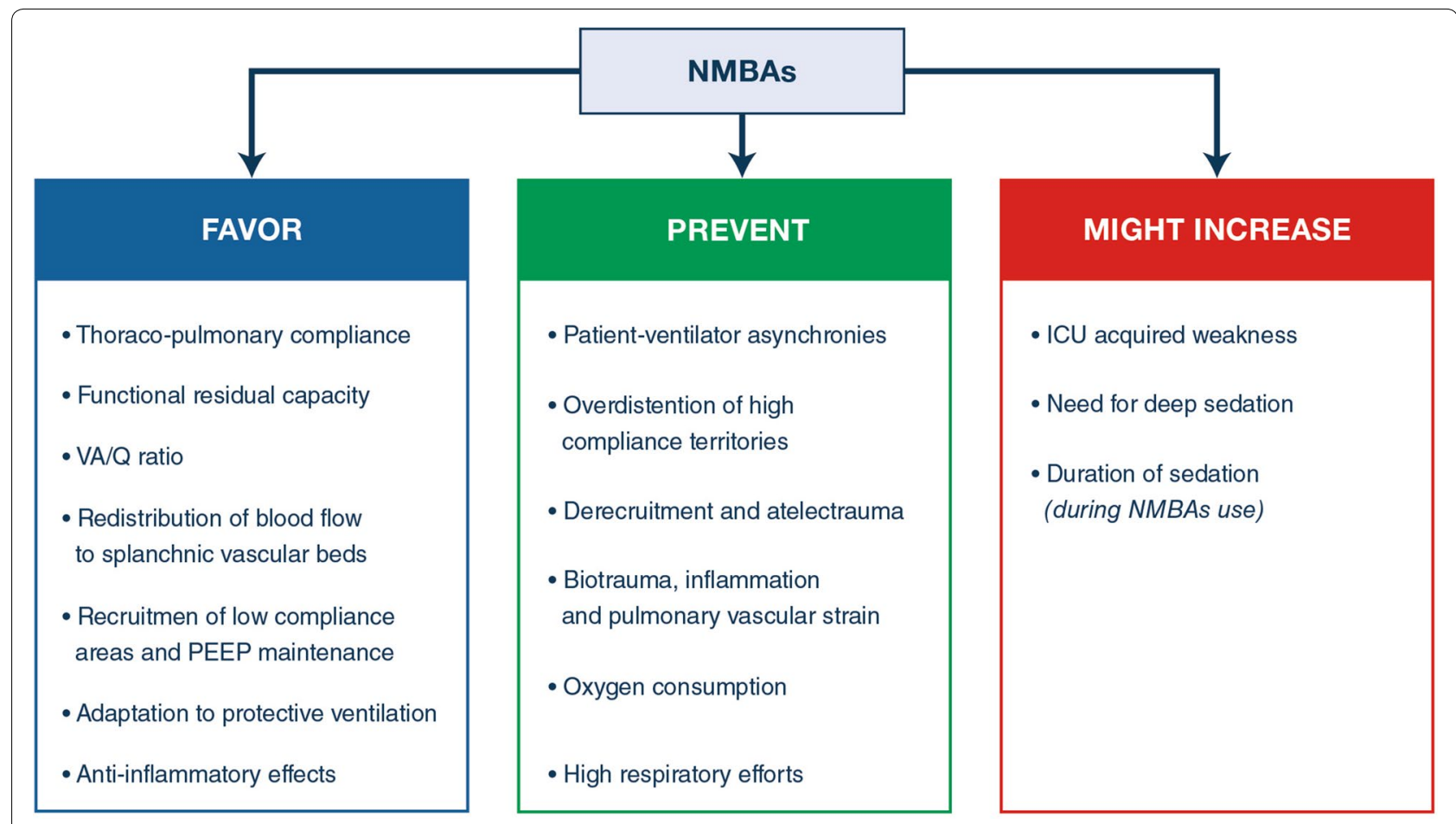

Fig. 1 Plausible beneficial effects of neuromuscular blocking agents (NMBAs) in ARDS patients

pressure, favouring the perfusion of ventilated areas and decreasing the intra-pulmonary shunt [23].

\section{Better regional distribution of the tidal volume}

NMBAs could avoid or limit the overdistension of high compliance territories and promoting the recruitment of areas with smaller compliance.

\section{Anti-inflammatory effects}

The lower production of proinflammatory cytokines in the lung and the blood reported in patients receiving cisatracurium [24] has suggested an "anti-inflammatory" role for NMBAs. Two mechanisms could be involved: first, a reduced inflammation through the reduction of ventilator-induced lung injury (VILI). The second hypothesis is a direct "anti-inflammatory" effect of cisatracurium (see "Biological effects" section).

\section{Biological effects of NMBAs}

NMBAs have multiple, potentially positive, biological effects in humans [25]. In patients with moderateto-severe ARDS, NMBAs administration has been associated with lower local and systemic release of inflammation, epithelial dysfunction, and endothelial injury biomarkers, such as IL-8, surfactant protein-D, and von Willebrand factor [24, 26].
The biological plausibility of a direct anti-inflammatory effect of cisatracurium is based on the broad expression of its receptor, alpha-1-nicotine receptor (nAChR $\alpha 1$ ), on epithelial cells, endothelial cells, leukocytes and fibroblasts [27-30] (Table S1, supplementary material 1). In the lungs, $\mathrm{nAChR} \alpha 1$ signals as an alternative receptor for urokinase on neutrophils, leading to the release of inflammatory cytokines such as IL- $1 \alpha$, TNF- $\alpha$, and macrophage inflammatory protein-2 [27]. An in vitro and in vivo animal study has been conducted to test the hypothesis that NMBAs are protective against biotrauma by their anti-inflammatory effects mediated by blocking the activity of $n A C h R \alpha 1$ on epithelial cells, endothelial cells, and leukocytes [31]. Cisatracurium had intrinsic anti-inflammatory properties and its lung protection was primarily independent of the effects of synchrony. Surrogates of lung injury, such as the wet to dry ratio and protein concentration in bronchoalveolar lavage fluid (BALF), were lower in rats treated with NMBA than in controls, in which perfect synchrony was achieved with anaesthesia alone. The anti-inflammatory effects of cisatracurium, as defined by the lower release of inflammatory cytokines by several cell types (epithelial, endothelial, and CD14+ cells) after challenge with LPS, BALF or plasma from ARDS patients, was mediated by nAChR $\alpha 1$ blockade. cisatracurium lacked its protective 
effects when nAChR $\alpha 1$ was stably knocked down in cell clones.

Nevertheless, the putative direct anti-inflammatory effect of cisatracurium needs to be counterbalanced by muscular atrophy and weakness associated with prolonged use of heavy sedation and NMBAs and addressed for its clinical implications.

\section{Risks of spontaneous breathing in ARDS}

The maintenance of physiological respiratory muscle activity in ventilated patients has recognized benefits compared to controlled ventilation including improved alveolar recruitment, increased cardiac output, increased blood flow to vital organs, prevention of peripheral muscles withering and reduced risk of diaphragm disuse atrophy [32]. However, accumulating evidence has alerted physicians, either directly or indirectly, to the risks of spontaneous breathing in various clinical settingse.g., non-intubated patients with acute respiratory failure [33], patients with ARDS [26, 34-38], patients with severe sepsis [39], patients with ARDS under ECMO [40], and paediatric patients with ARDS [41, 42]. Spontaneous breathing efforts may worsen lung injury, especially when the spontaneous effort is vigorous and/or lung injury is severe, termed patient self-inflicted lung injury (P-SILI) $[43,44]$. Several potential mechanisms to explain the harm of spontaneous breathing efforts are summarized as follows: (1) global and local overdistension, (2) increased lung perfusion, (3) patient-ventilator asynchrony, and (4) derecruitment with expiratory muscle activity (Fig. 2).

First, a vigorous spontaneous effort will increase global transpulmonary pressure by decreasing pleural pressure and thus increasing tidal volume (i.e., global overdistension). Notably, vigorous spontaneous efforts will also carry the potential risk to increase local lung stress and strain (i.e., local overdistension) of dependent lung regions by drawing gas from other lung regions (called the Pendelluft phenomenon [45]) or directly from the trachea, despite a limiting tidal volume. The cause may be that, in the 'solid-like' atelectatic lung, negative inspiratory pleural pressure following diaphragmatic contraction is not transmitted but rather localized in the dependent lung regions where negative inspiratory pleural pressure is first generated [45]. Recent experimental data have confirmed that the bulk of effort-dependent lung injury occurs in the dependent lung regions, the same region where vigorous effort causes greater inspiratory stress and stretch [46]. Second, a spontaneous effort will increase lung perfusion and potentially cause lung oedema in ARDS. Vigorous spontaneous efforts will increase transmural pressure across pulmonary vessels, i.e., a net distending pressure of intrathoracic vessels, by decreasing pleural pressure. This mechanism may explain why spontaneous effort causes lung oedema during volume-controlled mode [35], or during upper airway obstruction [47]. Third, high respiratory effort is known to be associated with breath stacking [48]. Breath stacking-i.e., the occurrence of two consecutive inspirations separated by a short expiratory time-is potentially injurious because the delivered tidal volume increases [16]. Fourth, during vigorous spontaneous breathing efforts, there is a shift of the diaphragm to the cephalad direction (to expire promptly) and a decrease in expiratory transpulmonary pressure despite the use of PEEP, causing derecruitment of dependent lung regions [13,34]. Finally, strong respiratory efforts during MV could be deleterious not only for the lungs but also for the diaphragm. The concept of diaphragm-protective ventilation has recently been proposed as a complementary strategy besides lung protective ventilation [43].

\section{Neuromuscular blockers and safety concerns ICU-acquired weakness}

Muscles weakness, long-term sequelae of critical illness, affects roughly two-thirds of ICU survivors [49]. This neurological complication is often associated with prolonged mechanical ventilation [50], and prolonged ICU and hospital lengths of stay [51]. Critical illness-associated neuromyopathy is likely caused by multiple factors, including systemic inflammation, metabolic disorders, and interventions [49]. Notably, historically, ICU-acquired neuromuscular weakness was first described in patients receiving a high dose of corticosteroids and neuromuscular blockade for severe asthma [52]. Neuromuscular blockade is used to paralyse the patient with the expectation that, when the drug is withdrawn, the patient resumes rapid normal neuromuscular function. Curare and non-depolarising NMBAs may cause prolonged muscular weakness [53]. The risk of persistent paralysis is higher in patients with hepatic or renal dysfunction because most nondepolarising NMBAs are cleared from the plasma by the kidneys and liver. Increased plasma clearance of NMBA also parallels the duration of drug infusion and concomitant use of aminoglycosides or corticosteroids. The chemical structure of many NMBAs incorporates a steroid moiety, which may increase the risk of ICUassociated weakness. A notable exception is cisatracurium, which is cleared by Hofmann elimination and has a different chemical structure. Indeed, no increase in ICU-associated weakness from cisatracurium was demonstrated in two large RCTs [37, 54].

Prolonged neuromuscular blockade may deregulate acetylcholine metabolism and/or the function of Ach receptors with the upregulation of receptor subtypes that are less sensitive to acetylcholine. In rats, a relatively 
Vigorous Spontaneous Effort Causes...

- Global Overdistension

- Maldistribution of Lung stress and Local Overdistension

- Increased Lung Perfusion and Lung Edema

- Patient-Ventilator Asynchrony

- Derecruitment with active exhalation
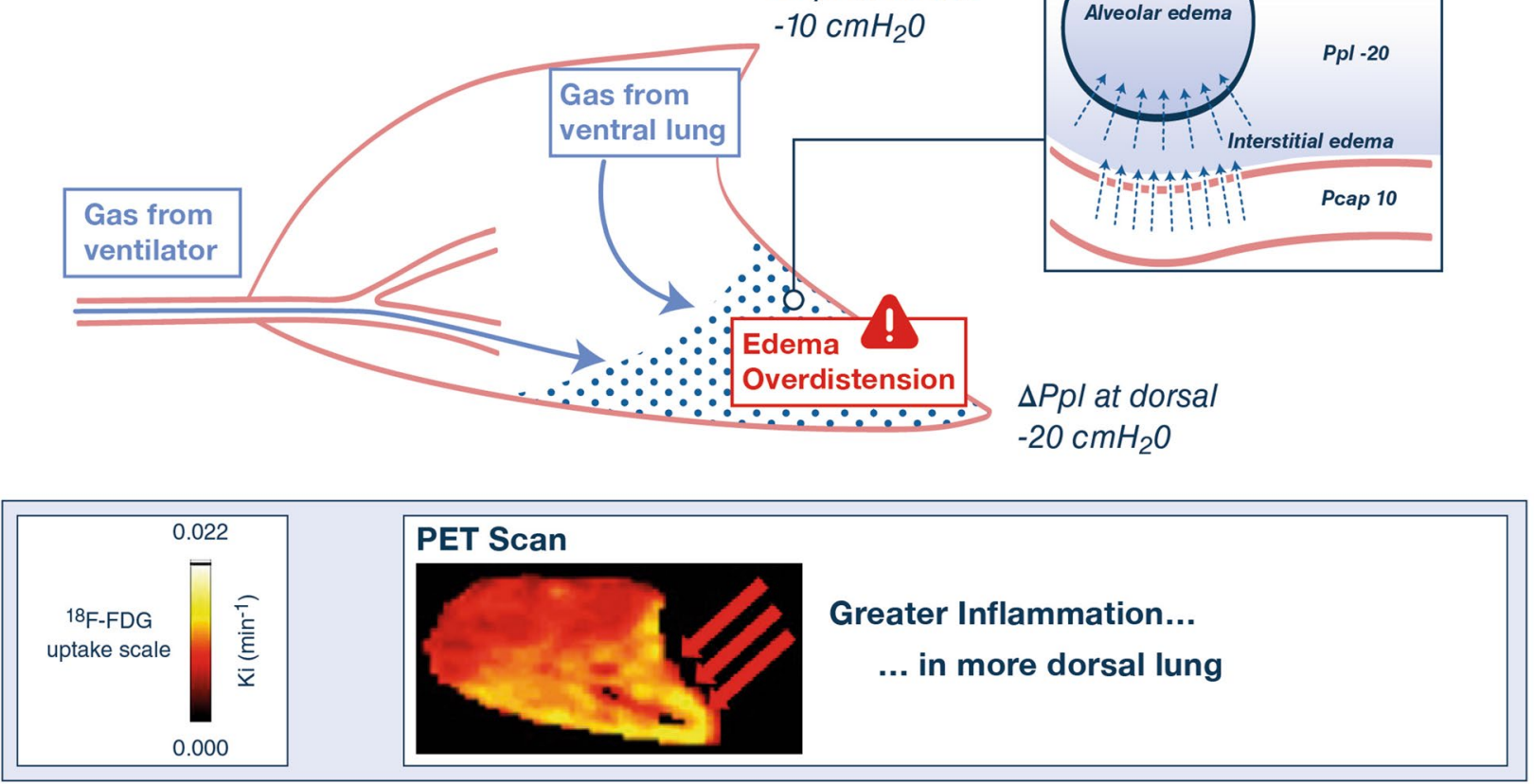

Fig. 2 Schema to explain the harm of vigorous spontaneous effort in ARDS. When vigorous spontaneous effort is preserved during mechanical ventilation, transpulmonary pressure (Paw-Ppl $=\mathrm{PL}$ ) reaches injuriously high, thereby increasing tidal volume and causing global overdistension. In addition, negative Ppl distends pulmonary capillary vessels and increases perfusion; the transmural pressure across pulmonary capillary vessels is increased (Pcap-Ppl $=+30$ ), promoting interstitial edema formation (right magnified panel). In the presence of injury, permeability is increased and, therefore, alveolar edema formation is accelerated (Right magnified panel). In ARDS, atelectasis is often present in dorsal (dependent) lung regions (dotted black area in lung). Since the presence of atelectatic 'solid-like' lung tissue may block the pressure transmission of negative $\triangle$ Ppl following diaphragmatic contraction, more negative $\triangle \mathrm{Ppl}$ is localized in dorsal lung regions (negative $\Delta \mathrm{Ppl}-20 \mathrm{cmH} 2 \mathrm{O} v \mathrm{~s}$. $-10 \mathrm{cmH} 2 \mathrm{O}$ in dorsal vs. ventral lung regions). In this way, greater local (dorsal) lung stress causes local overdistension by drawing gas from other lung regions-e.g., ventral lung (blue line; this is called pendelluft phenomenon [45]) or directly from a ventilator. Thus, the bulk of effort-dependent lung injury occurs in dorsal lung regions, where vigorous spontaneous effort causes greater inspiratory lung stress and stretch (three red lines in lower panel). In addition, vigorous spontaneous effort causes patient-ventilator asynchrony and derecruitment with active exhalation. Abbreviations: ARDS acute respiratory distress syndrome; Pcap capillary pressure; Pp/ pleural pressure

short experimental period was not associated with significant differences in the expression of known mediators of muscle atrophy, as demonstrated by similar diaphragm mRNA changes in expression of the muscle-specific ubiquitin ligases MuRF1 and Atrogin-1 [31]. However, the potential upregulation of $n A C h R \alpha 1$ in muscle and other cell types associated with the continuous infusion of cisatracurium warrants further investigation in the future.
Additionally, prolonged blockade of the neuromuscular junction may cause muscle atrophy, particularly in the presence of corticosteroids, ischaemia, acidosis or electrolyte disturbances [55]. Myopathy is a common complication of the exposure to corticosteroids, particularly fluorinated derivatives-e.g., dexamethasone. Notably, corticosteroid toxicity is potentiated by non-depolarising neuromuscular drugs such as pancuronium because they bind to a common corticosteroid receptor. ICU-acquired weakness is more likely to occur in patients receiving 
NMBA and corticosteroids concomitantly. It is also more likely to occur with a high dose of fluorinated corticosteroids and prolonged administration of a non-depolarising, long-acting NMBA. Nowadays, physicians are more likely to use short courses of short-acting NMBAs and a low dose of corticosteroids, which may be less likely to result in significant muscles weakness. In a recent metaanalysis of three trials of neuromuscular blockade for ARDS ( $n=431$ patients), $73 / 223$ and 62/208 (RR, 1.08; CI $0.83-1.41)$ patients had muscle weakness in the neuromuscular blockade and placebo groups, respectively [56]. Likewise, a systematic review and meta-analysis of 16 observational studies suggested that the administration of NMBAs might not be associated with increased risk of critical illness-associated neuromyopathy [57]. In practice, the duration of immobilization, severity of organ dysfunction, and metabolic and electrolytes disorders, as well as the concomitant use of other drugs altering neuromuscular function, may be more important to trigger ICU-acquired myopathy (or weakness) than neuromuscular blockade per se. Finally, a trial of cisatracurium for ARDS found no evidence of an increased risk of acute quadriplegic myopathy, although a high proportion of patients also received corticosteroids [37].

Nevertheless, in routine, ICU physicians should not combine fluorinated corticosteroids and non-depolarising NMBAs. We suggest using at a dose hydrocortisone not exceeding $300 \mathrm{mg}$ per day, and the duration of neuromuscular blockade should be as short as possible (ideally less than $48 \mathrm{~h}$ ). All other risk factors of critical illness-associated neuromyopathy should be avoidede.g., maintaining normal glucose, $\mathrm{pH}$ and electrolytes levels and avoiding aminoglycosides. Patients should benefit from prompt passive and active mobilization, as well as a rehabilitation programme.

\section{Ventilator-associated pneumonia (VAP)}

NMBAs have not been demonstrated to increase the risk of ventilator-associated pneumonia (VAP). An ancillary study of ACURASYS showed that NMBAs were not associated with a higher occurrence of bacterial VAP [58].

\section{Pressure and corneal ulcers}

In a prospective descriptive study focusing on more than 500 ICU long stays and evaluating pressure ulcers grade 2-4 occurrence, mechanical ventilation was associated with pressure sore occurrence but not NMBAs. Sedatives associated with turning, floating heels where negatively associated with pressure ulcers [59]. A recent international study did not identify the use of NMBAs as being associated with pressure ulcers [60]. Preventing the risk of corneal ulcers in deeply sedated patients receiving NMBAs need careful and daily ocular protection.

\section{Monitoring of NMBAs administration}

Despite the lack of robust evidence, monitoring neuromuscular blockade is recommended in ICU patients [11]. Monitoring the depth of neuromuscular blockade aims to ensure that objectives for muscle relaxation are reached in an anesthetized patient, that the lowest NMBAs dose is used (which could limit the development of ICU-acquired weakness), and, less frequently, that deleterious residual neuromuscular blockade after extubation is avoided. Different studies have shown that monitoring the level of neuromuscular blockade is associated with a reduction in the amount of NMBAs along with a decreased incidence of persistent neuromuscular weakness and that the management of blockade in ARDS patients by nurses is a secure procedure $[61,62]$. The depth of neuromuscular blockade should be assessed by repeated clinical and qualitative evaluation in addition to monitoring for adequate sedation and analgesia. The clinical evaluation based on the observation of skeletal muscle movement, respiratory efforts or the detection of patient-ventilator asynchronies must be coupled with a qualitative method to assess neuromuscular blockade. Train of four (TOF) supramaximal electrical impulses at a $2-\mathrm{Hz}$ frequency applied every $0.5 \mathrm{~s}$ to the ulnar nerve (less frequently the posterior tibial nerve) of a non-paralysed limb, or to the facial nerve, produces four visualized muscle twitches. TOF remains the easiest and most reliable method available for ICU patients. Increasing the dose of NMBA is associated with a decrease in the force of twitches. The evaluation of the decline in the twitch response can be performed by comparing the strength (TOF ratio) of the fourth twitch to that of the first twitch. However, the measurement of the TOF can be impaired by hypothermia, peripheral oedema, or incorrect positioning of electrodes. Notably, quantitative neuromuscular monitoring (using mechanomyography or acceleromyography, for example) is not routinely used in ICU patients.

When monitoring treatment with NMBAs, clinicians must be aware of the low correlation of blockade measured clinically and peripherally compared with that of the diaphragm [63]. Along these lines, differences exist in the time course of response to NMBAs between central muscles (diaphragm), which recover earlier, and peripheral muscles (abductor pollicis). Depending on the clinical situation, physicians can use the ulnar or facial site, to achieve a TOF goal of 0,1 or 2 twitches (as recommended for all ICU patients by the Neuromuscular Blockade Task Force [62]), or a TOF ratio exceeding 0.9. Furthermore, monitoring TOF recovery in response to facial nerve stimulation (as advised by the French recommendations in ICU patients [64]) before extubation could expose patients to aspiration [65], whereas facial or ulnar 
sites appear adequate to assess the depth of the relaxation of the diaphragm, particularly in ARDS patients.

\section{Sedation monitoring in patients receiving NMBAs}

Neither the ARDS et Curarisation Systematique (ACURASYS) study nor the Reevaluation of Systemic Early Neuromuscular Blockade (ROSE) study used sedation surveillance monitors in the NMBA arms; all the patients received deep sedation, and neither trial allowed decreasing the sedation after the initiation of NMBAs [37, 54]. Bispectral index (BIS) monitor is a noninvasive processed electroencephalogram that can identify accidental awareness with recall (AWR) in patients undergoing general anaesthesia [66]. BIS values of 40-60 minimize the risk of AWR in operating rooms [66]. Despite minimal data to corroborate its use in the ICU [67], BIS monitoring is becoming more common in mechanically ventilated patients undergoing paralysis [68]. The current NMBA guidelines do not recommend the use of sedation-monitoring devices to measure sedation [11]. There is a concern for discordance in BIS readings in patients with critical illness-associated encephalopathy [69]. Electromagnetic fields from other devices and instruments in the ICU environment might also affect BIS readings [67, 69]. The use of BIS monitors in clinical practice has been associated with increased rates of the down titration of sedatives, and the risk of under-sedating these patients needs to be always evaluated when using any monitoring devices to prevent long-term neuro-cognitive disorders, such as anxiety or post-traumatic stress disorder [66, 70]. BIS values should, moreover, be interpreted with caution as they have been shown to decline in fully awake volunteers under neuromuscular block [71, 72]. If BIS monitors are not employed for sedation monitoring, it is important to target deep sedation before NMBA initiation. Once deep sedation is achieved, a flat dose with no de-escalation should be implemented for the sedation instructions [68]. Importantly, RCTs of NMBA infusions in ARDS are limited to $48 \mathrm{~h}$, and adjunctive sedation monitors might be needed for prolonged NMBA use because of the risk of tachyphylaxis [37, 54].

\section{Outcomes of ARDS patients receiving NMBAs}

Seven randomized controlled trials (RCT) [13, 24, 37, 54, 73-75] have studied NMBA infusions in patients with moderate-severe ARDS (Table 2). Conflicting results from the two largest randomized controlled trials (RCTs) [37, 54] evaluating the role of NMBAs in ARDS have further tempered the enthusiasm for their use as a front-line adjunctive therapy [76]. Importantly, significant differences were found in the timing of enrolment, ventilatory and non-ventilatory strategies and the initial severity among the patients enrolled in ACURASYS compared with those in ROSE; thus, the differences in the study design and methodology might explain the differences in the reported mortality [77, 78]. In the first multicentre RCT [73], a significant improvement in the $\mathrm{PaO}_{2} / \mathrm{FiO}_{2}$ ratio and a strong tendency towards a lower mortality rate were observed in patients receiving NMBAs for $48 \mathrm{~h}$. The same group of authors [24] confirmed the beneficial effects of NMBAs on oxygenation and decreases in the plateau pressure, $\mathrm{FiO}_{2}$ and PEEP. Again, a trend towards decreased mortality in patients receiving NMBAs was observed. This was the rationale for designing the ACURASYS study [37], which showed that a strategy including cisatracurium is associated with an improvement in the adjusted 90-day survival rate compared with placebo. The 28-day mortality was $23.7 \%$ with cisatracurium and $33.3 \%$ with the placebo $(p=0.05)$. The beneficial effects of cisatracurium on mortality were mainly observed in patients with a $\mathrm{PaO}_{2} / \mathrm{FiO}_{2}$ ratio $<120 \mathrm{mmHg}$. The cisatracurium group had significantly more ventilator-free days than the placebo group during the first 28 days. NMBAs patients also presented less barotrauma. The PETAL (prevention and early treatment of acute lung injury) network aimed to re-evaluate the beneficial effects of NMBAs on mortality by designing the ROSE study [54] comparing the use of cisatracurium with management by light sedation very early in the course of moderate-to-severe ARDS. The primary endpoint was hospital mortality from any cause at day 90 . The trial was stopped at the second interim analysis for futility. Neither in-hospital mortality nor ventilator-free days at day 90 were different between the groups. NMBAs neither improved oxygenation nor decreased the rate of pneumothorax but were more frequently associated with serious cardiovascular adverse events. Significant methodological differences may explain these conflicting results between the ACURASYS and ROSE studies (Table 3) [37, 54]. First, the patients were included earlier in ROSE than in ACURASYS (the median times were $8 \mathrm{~h}$ and $16 \mathrm{~h}$, respectively). This shorter delay in the ROSE study could have compromised the adequate adjustment of both mechanical ventilation and sedation before inclusion. This finding likely explains why a significant proportion of eligible patients $(N=658)$ was excluded because of oxygenation improvement from inclusion to randomization [37], although patients with $\mathrm{PaO}_{2} / \mathrm{FiO}_{2}<150$ at inclusion could be included even if $\mathrm{PaO}_{2} / \mathrm{FiO}_{2}$ reached but not exceeded $200 \mathrm{mmHg}$ at the time of randomization (i.e., some patients had a $\mathrm{PaO}_{2} / \mathrm{FiO}_{2}>150$ ). Moreover, more patients in ROSE (17.1\%) than in ACURASYS (4.3\%) were excluded before enrollement because 


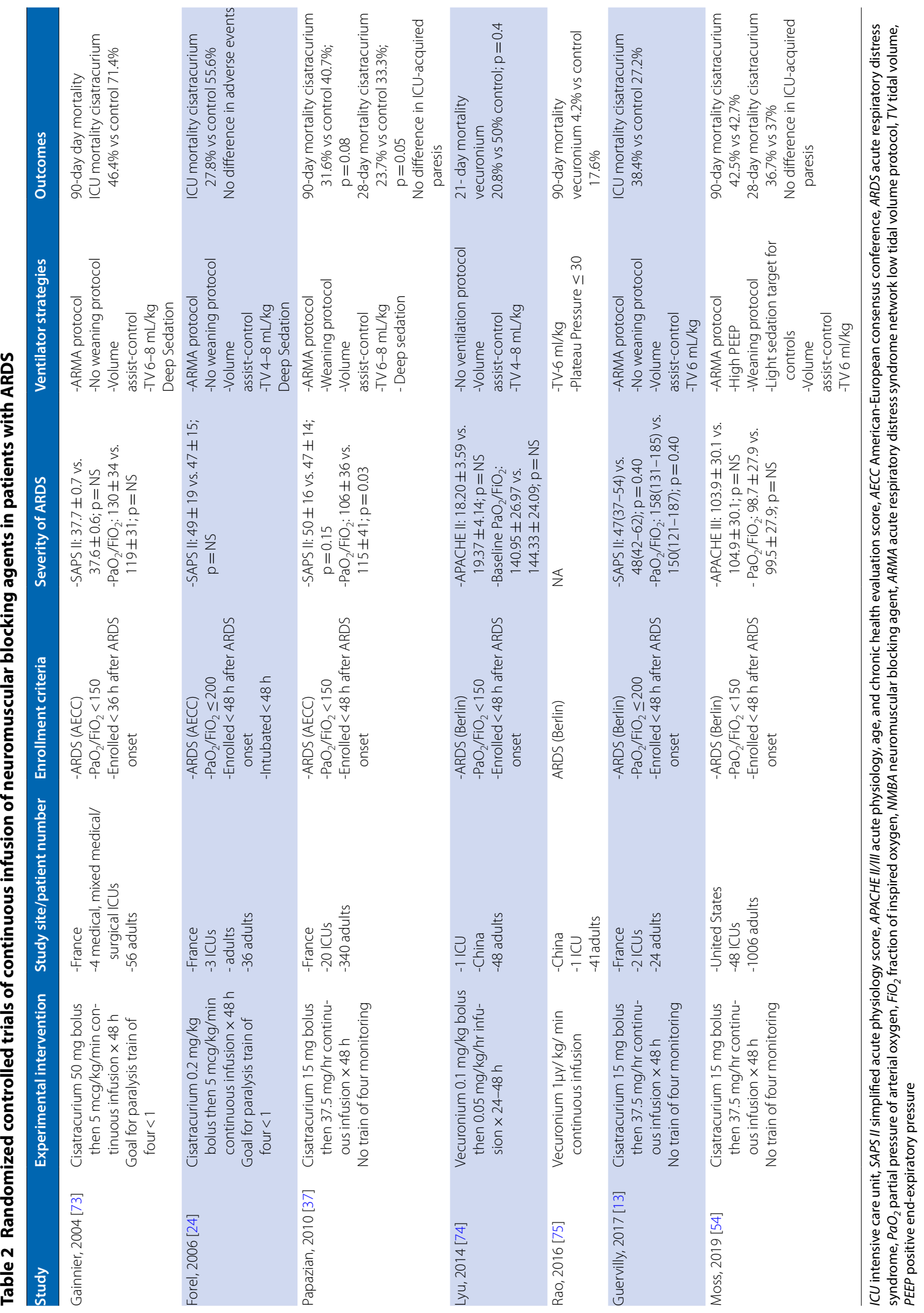


Table 3 A comparison of ACURASYS and ROSE studies on specific methodological aspects

\begin{tabular}{|c|c|c|}
\hline & ACURASYS [37] & ROSE $[54]$ \\
\hline Time from ARDS to inclusion (hours, median, IQR) & $16(6-29)$ & $7.6(3.7-15.6)$ \\
\hline Time from MV initiation to inclusion (hours, median, IQR) & $\begin{array}{l}\text { NMBAs } 22 \text { (9-41) } \\
\text { Placebo } 21 \text { (10-42) }\end{array}$ & NA \\
\hline $\begin{array}{l}\text { Excluded before enrollment because } \\
\text { already receiving NMBAs }(n)\end{array}$ & 42 & 655 \\
\hline NMBAs stop before the 48th hour & No & If $\mathrm{FiO}_{2} \leq 0.4$ and $\mathrm{PEEP} \leq 8 \mathrm{cmH}_{2} \mathrm{O}$ after $12 \mathrm{~h}$ \\
\hline NMBAs use after the 48th hour & Weaning attempt at day 3 if $\mathrm{FiO}_{2} \leq 0.6$ & Left to the discretion of the treating clinician \\
\hline $\begin{array}{l}\text { Patients from the control group } \\
\text { requiring NMBAs for injurious MV (\%) }\end{array}$ & 56 & $17-36$ \\
\hline PEEP strategy $\left(\mathrm{cmH}_{2} \mathrm{O}\right)$ & $\begin{array}{l}\text { Moderate PEEP (ARMA (6)) } \\
\text { NMBAs } 9.2 \pm 3.2 \\
\text { Placebo } 9.2 \pm 3.5\end{array}$ & 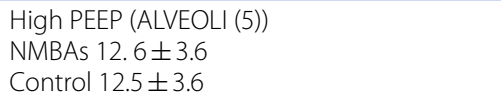 \\
\hline Prone positioning use (\%) & $\begin{array}{l}\text { NMBAs } 28 \\
\text { Placebo } 29\end{array}$ & $\begin{array}{l}\text { NMBAs } 16.8 \\
\text { Control } 14.9\end{array}$ \\
\hline MV weaning protocolized & Yes & NA \\
\hline 90-day mortality (\%) & $\begin{array}{l}\text { NMBAs } 31.6 \\
\text { Placebo } 41.4\end{array}$ & $\begin{array}{l}\text { NMBAs } 42.5 \\
\text { Control } 42.8\end{array}$ \\
\hline
\end{tabular}

ARDS acute respiratory distress syndrome, $H$ hour(s), $M V$ mechanical ventilation, $N A$ not available, NMBAs neuromuscular blocking agents, PEEP positive endexpiratory pressure

already receiving NMBAs [79], suggesting that some of them might have benefited from neuromuscular blockade. Third, strategies in both studies concerning PEEP adjustment were really different: a high PEEP (ALVEOLI high PEEP strategy [80]) was applied in the ROSE study, while a moderate PEEP (ARMA strategy [81]) was used in the ACURASYS study [37, 54]. A recent study has suggested that high levels of PEEP and recruitment manoeuvres could worsen the outcomes [82]. These differences in PEEP strategy could explain at least in part the discrepancies between ACURASYS and ROSE studies. Sedation strategies were also different during the first 2 days in the control group-light sedation in ROSE, heavy sedation in ACURASYS [37, 54]. Importantly, in this latter study [37], no difference was found between the two groups (NMBAs and placebo) regarding the amount of sedatives received (no "oversedation" in the placebo group). These differences in PEEP and sedation strategies may alter the level of VILI experience in both the control and intervention arms in both studies, highlighting the complex interplay among patient effort, sedation, NMBAs, and ventilator management in ARDS [76]. Another main difference was the lower use of prone positioning in ROSE ( $16 \%$ vs. $29 \%$ in ACURASYS) and the quick transition towards ventilatory modes, allowing spontaneous breathing and a weaning protocol in ACURASYS; no such protocol was reported in ROSE [37, 54]. Overall, these distinct approaches might explain the large difference in mortality observed between ACURASYS and ROSE regarding NMBA groups (90-day mortalities of $31.6 \%$ and $42.5 \%$, respectively); however, no difference was found between the two studies regarding the mortality of the control group [37, 54]. The conclusion that might be drawn from these two studies is that very early use of NMBAs, before optimizing MV and sedation, using a strategy involving high PEEP levels does not modify the outcomes $[37,54]$. Conversely, NMBAs (if sedation alone fails to improve respiratory status) integrated into an overall strategy including a reasoned use of PEEP, prone positioning and the rapid implementation of spontaneous breathing might improve the prognosis $[37,54]$. Including the results of ROSE, three meta-analyses showed a reduction of early (21to 28 -day) mortality $[83,84]$ and late (90-day or ICU) mortality $[83,85]$ in patients receiving NMBAs. Early improvement of oxygenation was also retrieved in three of these meta-analyses [83, 84, 86]. A lower risk of barotrauma and no effect on the occurrence of ICUacquired weakness were constantly reported.

\section{Partial neuromuscular blockade in patients with ARDS}

In patients with ARDS, respiratory drive may be excessive, mainly due to hypercapnic acidosis, hypoxemia, and inflammation, [87, 88] and lead to P-SILI [89]. Additionally, some preliminary data have suggested that prolonged strenuous diaphragm effort may result in load-induced diaphragm injury [90, 91]. The disadvantages of full neuromuscular blockade also include the risk for the development of diaphragm disuse atrophy [92], 


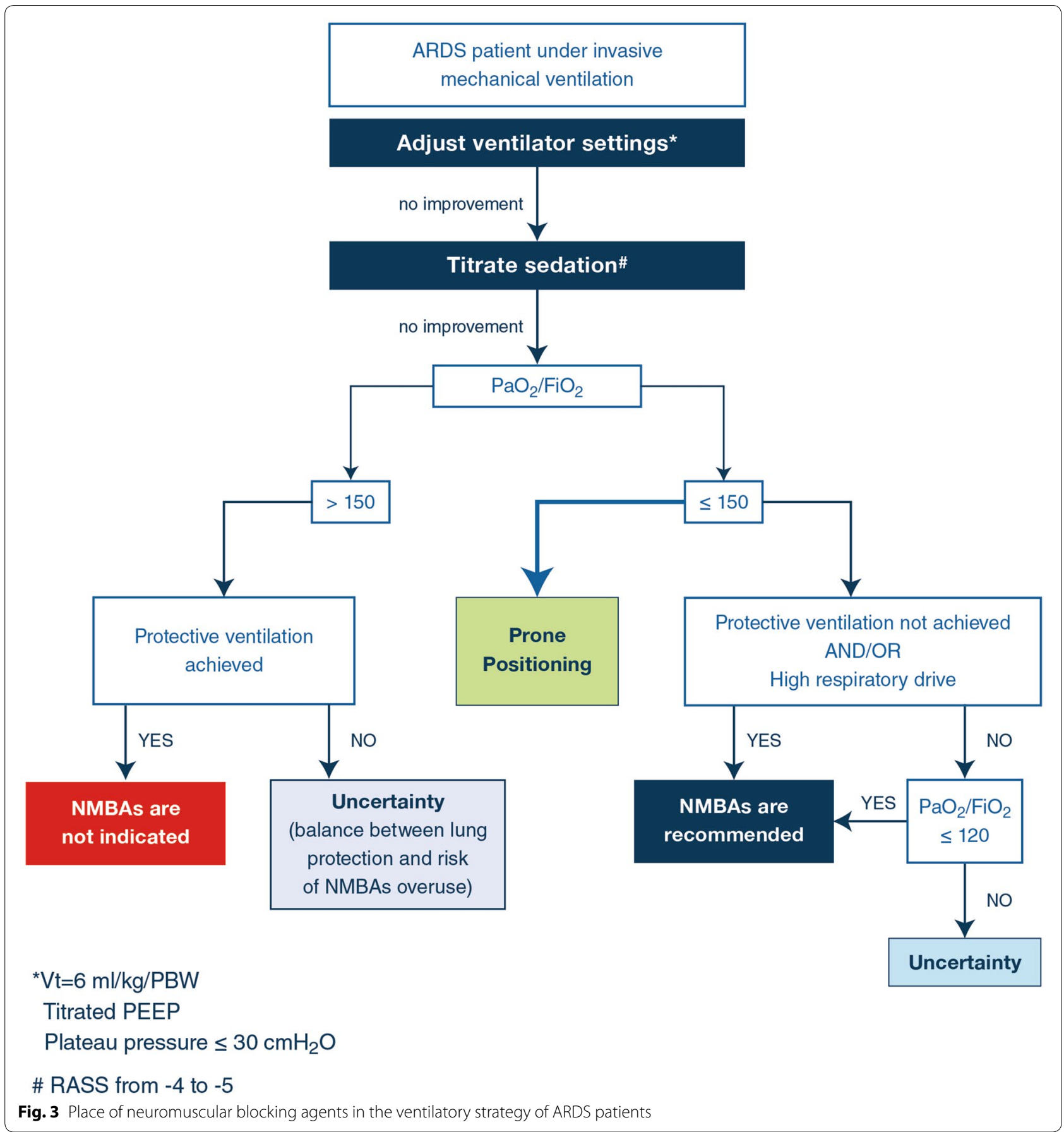

peripheral skeletal muscle atrophy due to immobility and the need for a high dose of sedatives. Accordingly, instead of complete diaphragm paralysis, an alternative approach would be to titrate the diaphragm effort to maintain a physiological effort. From this perspective, low-dose NMBAs ("partial neuromuscular blockade") is an interesting compromise between total diaphragm paralysis and injurious high breathing effort. Interestingly, it has been demonstrated more than 40 years ago that lowdose neuromuscular blockers (partial neuromuscular blockade) can be used to decrease respiratory muscle strength [93] while maintaining spontaneous breathing. The authors demonstrated that low-dose NMBA-induced respiratory muscle weakness but increased respiratory effort sensation. Therefore, partial neuromuscular blockade does not reduce respiratory drive, only respiratory 
Table 4 Summary of the main clinical recommendations for NMBAs use in clinical practice

\begin{tabular}{|c|c|}
\hline Issue & Recommendation \\
\hline Preferred neuromuscular blocker & Cisatracurium besilate ${ }^{1}$ \\
\hline Dosing recommendation & $\begin{array}{l}\text { No monitoring of neuromuscular block: } 37.5 \mathrm{mg} / \mathrm{h} \text { (ACURASYS dosing) } \\
\text { Monitoring of the TOF }{ }^{2} \text { : objective } 0 / 4 \text { response at the ulnar site or } 2 / 4 \text { at the facial site }[61,63]\end{array}$ \\
\hline Timing of administration & Early (acute phase of ARDS onset) and only after sedation/ventilator settings adjustments \\
\hline Sedation monitoring /goals & $\begin{array}{l}\text { RASS }-4 \text { to }-5 \text { before NMBAs } \\
\text { BIS } 40-60^{3}\end{array}$ \\
\hline Associated measures & $\begin{array}{l}\text { Protective MV (Vt, PEEP, Plateau pressure) } \\
\text { Prone positioning }\end{array}$ \\
\hline Duration of administration & $\begin{array}{l}48 \mathrm{~h} \text { at the acute phase of ARDS } \\
\text { Discontinue if } \mathrm{PaO}_{2} / \mathrm{FiO}_{2}>150 \mathrm{mmHg} \\
\text { After } 48 \mathrm{~h} \text {, reconsider the use of } \mathrm{NMBA} \text { at least every } 12 \mathrm{hrs}\end{array}$ \\
\hline Ventilatory settings after NMBAs stop & $\begin{array}{l}\text { Decrease sedation } \\
\text { Promote ventilatory modes allowing spontaneous breathing } \\
\text { Ensure protective MV }\end{array}$ \\
\hline ICU-acquired weakness prevention & $\begin{array}{l}\text { Limit concomitant high-dose corticosteroids use } \\
\text { Prefer non-steroidal compound (especially cisatracurium) }{ }^{4} \\
\text { Shorten NMBA administration } \\
\text { Avoid hyperglycemia, maintain normal pH and electrolytes }\end{array}$ \\
\hline Safety concerns & $\begin{array}{l}\text { Ocular care } \\
\text { Prevention of pressure ulcers (turning, nursing care) } \\
\text { Detect awareness: BIS monitoring, clinical evaluation (tachycardia, hypertension during stimulations) }\end{array}$ \\
\hline
\end{tabular}

$A R D S$ acute respiratory distress syndrome, $B I S$ bis spectral index, $M V$ mechanical ventilation, NMBAs neuromuscular blocking agents, $P E E P$ positive end-expiratory pressure, RASS richmond agitation-sedation scale, $V t$ tidal volume

1 Cisatracurium besilate was used in the largest RCT evaluating the effects of NMBAs on mortality (see Table 3). Recent data suggest that ARDS patients receiving cisatracurium had a lower duration of MV and ICU length of stay as compared with those receiving vecuronium [9]. Non-steroidal compounds (benzylisoquinolinium) are less associated with ICU-acquired weakness

2 TOF: train of four

3 Use with caution, BIS values might be decreased by NMBAs use

${ }^{4}$ No increase in ICU-associated weakness from cisatracurium was demonstrated in two large RCTs [37, 54]and in three recent meta-analysis [83, 84, 86]

muscle effort. In a proof-of-concept study recruiting patients with moderate ARDS and high respiratory drive, the feasibility of partial neuromuscular blockade was evaluated in patients on pressure support ventilation [94]. Careful titration with rocuronium decreased the tidal volume from $9.3 \pm 0.6 \mathrm{ml} / \mathrm{kg}$ to $5.6 \pm 0.2 \mathrm{ml} / \mathrm{kg}$, fulfilling the criteria for lung-protective ventilation. For reasons incompletely understood, the reduction in minute ventilation due to a reduced tidal volume was not completely compensated by an increase in respiratory rate. Accordingly, patients developed mild respiratory acidosis with partial neuromuscular blockade. After rocuronium titration, the transdiaphragmatic pressure was decreased to $\pm 5.0 \mathrm{cmH}_{2} \mathrm{O}$, well within the physiological range for diaphragm activity during tidal breathing in healthy subjects. Although this strategy was applied for only $2 \mathrm{~h}$ in highly selected patients, it suggests that partial neuromuscular blockade is a feasible and safe strategy to deliver lung- and diaphragm-protective ventilation in patients with a high respiratory effort. However, future clinical studies are warranted to confirm the safety and efficacy of prolonged partial neuromuscular relaxation in ventilated patients.

\section{Future prospects and conclusions}

Pharmacologic strategies such as NMBAs should not be used routinely in all patients with moderate-severe ARDS but need to be customized for the appropriate patient at the right time to evaluate their benefit [77]. The initial management of ARDS must follow a lung-protective strategy with the optimization of PEEP and sedation for individual patients [95]. After this initial optimization of mechanical ventilation and sedation, clinicians must integrate the use of NMBAs in a step-up fashion based on objective physiologic criteria $\left(\mathrm{PaO}_{2} / \mathrm{FiO}_{2}\right)$ and the presence of either asynchrony or unsafe ventilation [95]. Gas exchange improvement should prompt physicians to stop NMBAs and encourage spontaneous breathing activity (Fig. 3).

More research is needed to adjust the use of NMBAs in ARDS patients. First, the benefits observed may not apply to all NMBAs, considering that cisatracurium besylate has been used in all RCTs. Second, the optimal duration of infusion needs to be evaluated according to the patients' profiles and/or responses to the treatments. Twenty-four hours of paralysis may be sufficient in some cases with prompt improvement. By contrast, in some 
patients with very severe ARDS (including those requiring ECMO with persistent high respiratory drive and/or prone positioning), longer durations are often required. Because NMBAs were used in more than $85 \%$ of patients from the PROSEVA study [96], whether the use of NMBAs is required in all moderate-to-severe ARDS patients requiring prone positioning must be specified. Third, the place of NMBAs to improve respiratory system mechanics in patients without moderate-to-severe hypoxemia but with large swings in transpulmonary pressure deserves to be further explored. Finally, clinicians can be relieved regarding the potential harmful effects of NMBAs. Indeed, the use of a short course of a recent NMBA was not associated with an increased incidence of ICU-acquired neuromyopathy [37, 54] (Table 3).

Considering the current definition of ARDS, the use of NMBAs should be considered during the early phase of severe ARDS for patients who require deep sedation to facilitate lung-protective ventilation or prone positioning [97]. However, as stated in a recent guideline [97], NMBA infusion must be discussed only after optimizing mechanical ventilation and sedation (the ACURASYS strategy). The use of NMBAs should be integrated into an overall strategy including the reduction of the tidal volume, a reasoned use of PEEP according to its impact on gas exchange and the haemodynamic status, the use of prone positioning and preferential choice of a ventilatory mode allowing spontaneous ventilation as soon as possible [95] (Table 4). Partial neuromuscular blockade needs further clinical evaluation but is a promising strategy.

\section{Electronic supplementary material}

The online version of this article (https://doi.org/10.1007/s00134-020-06297-8) contains supplementary material, which is available to authorized users.

\footnotetext{
Author details

${ }^{1}$ Assistance Publique - Hôpitaux de Marseille, Hôpital Nord, Médecine Intensive Réanimation, 13015 Marseille, France. ${ }^{2}$ Faculté de médecine, Groupe de recherche en Réanimation et Anesthésie de Marseille pluridisciplinaire $($ GRAM +), Centre d'Etudes et de Recherches sur les Services de Santé et qualité de vie EA 3279, Aix-Marseille Université, 13005 Marseille, France. ${ }^{3}$ The Department of Anesthesiology and Intensive Care Medicine, Osaka University Graduate School of Medicine, Suita, Japan. ${ }^{4}$ School of Medicine Simone Veil, Lab of Infection and Inflammation, U1173, RHU-RECORDS, FHU SEPSIS, INSERM, Université Paris Saclay, UVSQ, Hôpital Raymond Poincaré (APHP), 104 boulevard Raymond Poincaré, 92380 Garches, France. ${ }^{5}$ Department of Critical Care, Respiratory Institute, Cleveland Clinic Lerner College of Medicine of Case Western Reserve University, Cleveland, OH 44195, USA. ${ }^{6}$ Department of Surgical Sciences, Anaesthesia and Intensive Care Medicine, Città della Salute e della Scienza Hospital, University of Turin, Turin, Italy. ${ }^{7}$ Centre Hospitalier Universitaire de Rennes, Maladies Infectieuses et Réanimation Médicale, Inserm-CIC-1414, Université Rennes I, IFR 140, F-35033 Rennes, France. ${ }^{8}$ Department of Intensive Care Medicine, Amsterdam University Medical Center, Location VUmc, Amsterdam, The Netherlands. ${ }^{9}$ Réanimation Chirurgicale, Centre Hospitalier Universitaire de Montpellier, Hôpital St-Eloi, Montpellier, France. ${ }^{10}$ Division of Pulmonary Sciences and Critical Care Medicine, University of Colorado School of Medicine, Aurora, CO, USA.
}

\section{Acknowledgements}

This manuscript was edited for proper English, grammar, punctuation, spelling, and overall style by American Journal Experts

\section{Funding}

No financial support.

\section{Compliance with ethical standards}

\section{Conflicts of interest}

SH has no conflict of interest. LP received consultancy fees from Air Liquide MS, Faron and MSD. VF has not conflict of interest. LH received a research grant from Liberate Medical, USA and speakers fee from Getinge, Sweden and Liberate Medical, USA. PDS has no conflicts of interest. TY has no conflicts of interest. AG has no conflicts of interest, SJ reports consulting fees from Drager, Fresenius-Xenios, Baxter, Medtronic, and Fisher and Paykel. DA has no conflicts of interest.

\section{Publisher's Note}

Springer Nature remains neutral with regard to jurisdictional claims in published maps and institutional affiliations.

Received: 13 September 2020 Accepted: 13 October 2020

Published online: 7 November 2020

\section{References}

1. Courcelle R, Gaudry S, Serck N, Blonz G, Lascarrou JB, Grimaldi D, on behalf the Csg (2020) Neuromuscular blocking agents (NMBA) for COVID19 acute respiratory distress syndrome: a multicenter observational study. Crit Care 24:446

2. Arroliga AC, Thompson BT, Ancukiewicz M, Gonzales JP, Guntupalli KK, Park PK, Wiedemann HP, Anzueto A, Acute Respiratory Distress Syndrome N (2008) Use of sedatives, opioids, and neuromuscular blocking agents in patients with acute lung injury and acute respiratory distress syndrome. Crit Care Med 36:1083-1088

3. Guerin C, Mancebo J (2015) Prone positioning and neuromuscular blocking agents are part of standard care in severe ARDS patients: yes. Intensive Care Med 41:2195-2197

4. Combes A, Hajage D, Capellier G, Demoule A, Lavoue S, Guervilly C, Da Silva D, Zafrani L, Tirot P, Veber B, Maury E, Levy B, Cohen Y, Richard C, Kalfon P, Bouadma L, Mehdaoui H, Beduneau G, Lebreton G, Brochard L, Ferguson ND, Fan E, Slutsky AS, Brodie D, Mercat A, Eolia Trial Group R, Ecmonet (2018) Extracorporeal membrane oxygenation for severe acute respiratory distress Syndrome. N Engl J Med 378:1965-1975

5. Burry LD, Seto K, Rose L, Lapinsky SC, Mehta S (2013) Use of sedation and neuromuscular blockers in critically ill adults receiving high-frequency oscillatory ventilation. Ann Pharmacother 47:1122-1129

6. Naguib M, Flood P, McArdle JJ, Brenner HR (2002) Advances in neurobiology of the neuromuscular junction: implications for the anesthesiologist. Anesthesiology 96:202-231

7. Testelmans D, Maes K, Wouters P, Powers SK, Decramer M, Gayan-Ramirez $\mathrm{G}$ (2007) Infusions of rocuronium and cisatracurium exert different effects on rat diaphragm function. Intensive Care Med 33:872-879

8. De Wolf AM, Freeman JA, Scott VL, Tullock W, Smith DA, Kisor DF, Kerls S, Cook DR (1996) Pharmacokinetics and pharmacodynamics of cisatracurium in patients with end-stage liver disease undergoing liver transplantation. Br J Anaesth 76:624-628

9. Sottile PD, Kiser TH, Burnham EL, Ho PM, Allen RR, Vandivier RW, Moss M, Colorado Pulmonary Outcomes Research G (2018) An observational study of the efficacy of cisatracurium compared with vecuronium in patients with or at risk for acute respiratory distress syndrome. Am J Respir Crit Care Med 197:897-904

10. Szakmany T, Woodhouse T (2015) Use of cisatracurium in critical care: a review of the literature. Minerva Anestesiol 81:450-460

11. Murray MJ, DeBlock H, Erstad B, Gray A, Jacobi J, Jordan C, McGee W, McManus C, Meade M, Nix S, Patterson A, Sands MK, Pino R, Tescher A, Arbour R, Rochwerg B, Murray CF, Mehta S (2016) Clinical practice 
guidelines for sustained neuromuscular blockade in the adult critically III patient. Crit Care Med 44:2079-2103

12. Slutsky AS (2010) Neuromuscular blocking agents in ARDS. N Engl J Med 363:1176-1180

13. Guervilly C, Bisbal M, Forel JM, Mechati M, Lehingue S, Bourenne J, Perrin G, Rambaud R, Adda M, Hraiech S, Marchi E, Roch A, Gainnier M, Papazian $L$ (2017) Effects of neuromuscular blockers on transpulmonary pressures in moderate to severe acute respiratory distress syndrome. Intensive Care Med 43:408-418

14. Yoshida T, Nakahashi S, Nakamura MAM, Koyama Y, Roldan R, Torsani V, De Santis RR, Gomes S, Uchiyama A, Amato MBP, Kavanagh BP, Fujino Y (2017) Volume-controlled ventilation does not prevent injurious inflation during spontaneous effort. Am J Respir Crit Care Med 196:590-601

15. Beitler JR, Sands SA, Loring SH, Owens RL, Malhotra A, Spragg RG, Matthay MA, Thompson BT, Talmor D (2016) Quantifying unintended exposure to high tidal volumes from breath stacking dyssynchrony in ARDS: the BREATHE criteria. Intensive Care Med 42:1427-1436

16. Akoumianaki E, Lyazidi A, Rey N, Matamis D, Perez-Martinez N, Giraud R, Mancebo J, Brochard L, Richard JM (2013) Mechanical ventilationinduced reverse-triggered breaths: a frequently unrecognized form of neuromechanical coupling. Chest 143:927-938

17. Bourenne J, Guervilly C, Mechati M, Hraiech S, Fraisse M, Bisbal M, Roch A, Forel JM, Papazian L, Gainnier M (2019) Variability of reverse triggering in deeply sedated ARDS patients. Intensive Care Med 45:725-726

18. Blanch L, Villagra A, Sales B, Montanya J, Lucangelo U, Lujan M, GarciaEsquirol O, Chacon E, Estruga A, Oliva JC, Hernandez-Abadia A, Albaiceta GM, Fernandez-Mondejar E, Fernandez R, Lopez-Aguilar J, Villar J, Murias G, Kacmarek RM (2015) Asynchronies during mechanical ventilation are associated with mortality. Intensive Care Med 41:633-641

19. Manthous CA, Hall JB, Kushner R, Schmidt GA, Russo G, Wood LD (1995) The effect of mechanical ventilation on oxygen consumption in critically ill patients. Am J Respir Crit Care Med 151:210-214

20. Marik PE, Kaufman D (1996) The effects of neuromuscular paralysis on systemic and splanchnic oxygen utilization in mechanically ventilated patients. Chest 109:1038-1042

21. Schreiber T, Hueter L, Gaser E, Schmidt B, Schwarzkopf K, Karzai W (2007) Effects of a catecholamine-induced increase in cardiac output on lung injury after experimental unilateral pulmonary acid instillation. Crit Care Med 35:1741-1748

22. Hedenstierna G, Strandberg A, Brismar B, Lundquist H, Svensson L, Tokics $L$ (1985) Functional residual capacity, thoracoabdominal dimensions, and central blood volume during general anesthesia with muscle paralysis and mechanical ventilation. Anesthesiology 62:247-254

23. Tokics L, Hedenstierna G, Svensson L, Brismar B, Cederlund T, Lundquist H, Strandberg A (1996) V/Q distribution and correlation to atelectasis in anesthetized paralyzed humans. J Appl Physiol 81:1822-1833

24. Forel JM, Roch A, Marin V, Michelet P, Demory D, Blache JL, Perrin G, Gainnier M, Bongrand P, Papazian L (2006) Neuromuscular blocking agents decrease inflammatory response in patients presenting with acute respiratory distress syndrome. Crit Care Med 34:2749-2757

25. Sottile PD, Albers D, Higgins C, McKeehan J, Moss MM (2018) The association between ventilator dyssynchrony, delivered tidal volume, and sedation using a novel automated ventilator dyssynchrony detection algorithm. Crit Care Med 46:e151-e157

26. Sottile PD, Albers D, Moss MM (2018) Neuromuscular blockade is associated with the attenuation of biomarkers of epithelial and endothelial injury in patients with moderate-to-severe acute respiratory distress syndrome. Crit Care 22:63

27. Abraham E, Gyetko MR, Kuhn K, Arcaroli J, Strassheim D, Park JS, Shetty S, Idell S (2003) Urokinase-type plasminogen activator potentiates lipopolysaccharide-induced neutrophil activation. J Immunol 170:5644-5651

28. Zhang G, Kernan KA, Thomas A, Collins S, Song Y, Li L, Zhu W, Leboeuf RC, Eddy AA (2009) A novel signaling pathway: fibroblast nicotinic receptor alpha1 binds urokinase and promotes renal fibrosis. J Biol Chem 284:29050-29064

29. Zhang G, Marshall AL, Thomas AL, Kernan KA, Su Y, LeBoeuf RC, Dong XR, Tchao BN (2011) In vivo knockdown of nicotinic acetylcholine receptor alpha1 diminishes aortic atherosclerosis. Atherosclerosis 215:34-42

30. Zhang G, Thomas AL, Marshall AL, Kernan KA, Su Y, Zheng Y, Takano J, Saido TC, Eddy AA (2011) Nicotinic acetylcholine receptor alpha1 promotes calpain-1 activation and macrophage inflammation in hypercholesterolemic nephropathy. Lab Invest 91:106-123

31. Fanelli V, Morita Y, Cappello P, Ghazarian M, Sugumar B, Delsedime L, Batt J, Ranieri VM, Zhang H, Slutsky AS (2016) Neuromuscular blocking agent cisatracurium attenuates lung injury by inhibition of nicotinic acetylcholine receptor-alpha1. Anesthesiology 124:132-140

32. Putensen C, Muders T, Varelmann D, Wrigge H (2006) The impact of spontaneous breathing during mechanical ventilation. Curr Opin Crit Care 12:13-18

33. Tonelli R, Fantini R, Tabbi L, Castaniere I, Pisani L, Pellegrino MR, Della Casa G, D'Amico R, Girardis M, Nava S, Clini EM, Marchioni A (2020) Early inspiratory effort assessment by esophageal manometry predicts noninvasive ventilation outcome in de novo respiratory failure. A pilot study. Am J Respir Crit Care Med 202:558-567

34. Coggeshall JW, Marini JJ, Newman JH (1985) Improved oxygenation after muscle relaxation in adult respiratory distress syndrome. Arch Intern Med 145:1718-1720

35. Kallet RH, Alonso JA, Luce JM, Matthay MA (1999) Exacerbation of acute pulmonary edema during assisted mechanical ventilation using a lowtidal volume, lung-protective ventilator strategy. Chest 116:1826-1832

36. Leray V, Bourdin G, Flandreau G, Bayle F, Wallet F, Richard JC, Guerin C (2010) A case of pneumomediastinum in a patient with acute respiratory distress syndrome on pressure support ventilation. Respir Care 55:770-773

37. Papazian L, Forel JM, Gacouin A, Penot-Ragon C, Perrin G, Loundou A, Jaber S, Arnal JM, Perez D, Seghboyan JM, Constantin JM, Courant P, Lefrant JY, Guerin C, Prat G, Morange S, Roch A (2010) Neuromuscular blockers in early acute respiratory distress syndrome. N Engl J Med 363:1107-1116

38. Goligher EC, Dres M, Fan E, Rubenfeld GD, Scales DC, Herridge MS, Vorona S, Sklar MC, Rittayamai N, Lanys A, Murray A, Brace D, Urrea C, Reid WD, Tomlinson G, Slutsky AS, Kavanagh BP, Brochard LJ, Ferguson ND (2018) Mechanical ventilation-induced diaphragm atrophy strongly impacts clinical outcomes. Am J Respir Crit Care Med 197:204-213

39. Steingrub JS, Lagu T, Rothberg MB, Nathanson BH, Raghunathan K, Lindenauer PK (2014) Treatment with neuromuscular blocking agents and the risk of in-hospital mortality among mechanically ventilated patients with severe sepsis. Crit Care Med 42:90-96

40. Mauri T, Langer T, Zanella A, Grasselli G, Pesenti A (2016) Extremely high transpulmonary pressure in a spontaneously breathing patient with early severe ARDS on ECMO. Intensive Care Med 42:2101-2103

41. Lalgudi Ganesan S, Jayashree M, Chandra Singhi S, Bansal A (2018) Airway pressure release ventilation in pediatric acute respiratory distress syndrome. A randomized controlled trial. Am J Respir Crit Care Med 198:1199-1207

42. Rossi FS, Costa ELV, lope DDM, Pacce PHD, Cestaro C, Braz LZ, Bousso A, Amato MBP (2019) Pendelluft detection using electrical impedance tomography in an infant. Keep those images in mind. Am J Respir Crit Care Med 200:1427-1429

43. Goligher EC, Dres M, Patel BK, Sahetya SK, Beitler JR, Telias I, Yoshida T, Vaporidi K, Grieco DL, Schepens T, Grasselli G, Spadaro S, Dianti J, Amato M, Bellani G, Demoule A, Fan E, Ferguson ND, Georgopoulos D, Guerin C, Khemani RG, Laghi F, Mercat A, Mojoli F, Ottenheijm CAC, Jaber S, Heunks L, Mancebo J, Mauri T, Pesenti A, Brochard L, Pleural Pressure Working Group ARFSotESoICM (2020) Lung and diaphragm-protective ventilation. Am J Respir Crit Care Med 202:950-961

44. Yoshida T, Fujino Y, Amato MB, Kavanagh BP (2017) Fifty years of research in ARDS. Spontaneous breathing during mechanical ventilation. Risks, mechanisms, and management. Am J Respir Crit Care Med 195:985-992

45. Yoshida T, Torsani V, Gomes S, De Santis RR, Beraldo MA, Costa EL, Tucci MR, Zin WA, Kavanagh BP, Amato MB (2013) Spontaneous effort causes occult pendelluft during mechanical ventilation. Am J Respir Crit Care Med 188:1420-1427

46. Morais CCA, Koyama Y, Yoshida T, Plens GM, Gomes S, Lima CAS, Ramos OPS, Pereira SM, Kawaguchi N, Yamamoto H, Uchiyama A, Borges JB, Vidal Melo MF, Tucci MR, Amato MBP, Kavanagh BP, Costa ELV, Fujino Y (2018) High positive end-expiratory pressure renders spontaneous effort noninjurious. Am J Respir Crit Care Med 197:1285-1296

47. Oswalt CE, Gates GA, Holmstrom MG (1977) Pulmonary edema as a complication of acute airway obstruction. JAMA 238:1833-1835 
48. Thille AW, Rodriguez P, Cabello B, Lellouche F, Brochard L (2006) Patientventilator asynchrony during assisted mechanical ventilation. Intensive Care Med 32:1515-1522

49. De Jonghe B, Sharshar T, Lefaucheur JP, Authier FJ, Durand-Zaleski I, Boussarsar M, Cerf C, Renaud E, Mesrati F, Carlet J, Raphael JC, Outin H, BastujiGarin S (2002) Paresis acquired in the intensive care unit: a prospective multicenter study. JAMA 288:2859-2867

50. De Jonghe B, Bastuji-Garin S, Durand MC, Malissin I, Rodrigues P, Cerf C, Outin H, Sharshar T, Groupe de Reflexion et d'Etude des Neuromyopathies en R (2007) Respiratory weakness is associated with limb weakness and delayed weaning in critical illness. Crit Care Med 35:2007-2015

51. Sharshar T, Bastuji-Garin S, Stevens RD, Durand MC, Malissin I, Rodriguez $P$, Cerf C, Outin H, De Jonghe B (2009) Presence and severity of intensive care unit-acquired paresis at time of awakening are associated with increased intensive care unit and hospital mortality. Crit Care Med 37:3047-3053

52. MacFarlane IA, Rosenthal FD (1977) Severe myopathy after status asthmaticus. Lancet 2:615

53. Lacomis D, Giuliani MJ, Van Cott A, Kramer DJ (1996) Acute myopathy of intensive care: clinical, electromyographic, and pathological aspects. Ann Neurol 40:645-654

54. Moss M, Huang DT, Brower RG, Ferguson ND, Ginde AA, Gong MN, Grissom CK, Gundel S, Hayden D, Hite RD, Hou PC, Hough CL, Iwashyna TJ, Khan A, Liu KD, Talmor D, Thompson BT, Ulysse CA, Yealy DM, Angus DC (2019) Early neuromuscular blockade in the acute respiratory distress syndrome. N Engl J Med 380:1997-2008

55. Segredo V, Caldwell JE, Matthay MA, Sharma ML, Gruenke LD, Miller RD (1992) Persistent paralysis in critically ill patients after long-term administration of vecuronium. N Engl J Med 327:524-528

56. Alhazzani W, Alshahrani M, Jaeschke R, Forel JM, Papazian L, Sevransky J, Meade MO (2013) Neuromuscular blocking agents in acute respiratory distress syndrome: a systematic review and meta-analysis of randomized controlled trials. Crit Care 17:R43

57. Puthucheary Z, Rawal J, Ratnayake G, Harridge S, Montgomery H, Hart N (2012) Neuromuscular blockade and skeletal muscle weakness in critically ill patients: time to rethink the evidence? Am J Respir Crit Care Med 185:911-917

58. Forel JM, Voillet F, Pulina D, Gacouin A, Perrin G, Barrau K, Jaber S, Arnal JM, Fathallah M, Auquier P, Roch A, Azoulay E, Papazian L (2012) Ventilator-associated pneumonia and ICU mortality in severe ARDS patients ventilated according to a lung-protective strategy. Crit Care 16:R65

59. Nijs N, Toppets A, Defloor T, Bernaerts K, Milisen K, Van Den Berghe G (2009) Incidence and risk factors for pressure ulcers in the intensive care unit. J Clin Nurs 18:1258-1266

60. Labeau SO, Afonso E, Benbenishty J, Blackwood B, Boulanger C, Brett SJ, Calvino-Gunther S, Chaboyer W, Coyer F, Deschepper M, François G, Honore PM, Jankovic R, Khanna AK, Llaurado-Serra M, Lin F, Rose L, Rubulotta F, Saager L, Williams G, Blot SI, on behalf of the Decub IST, the European Society of Intensive Care Medicine Trials Group C (2020) Prevalence, associated factors and outcomes of pressure injuries in adult intensive care unit patients: the DecublCUs study. Intensive Care Med. https://doi.org/10.1007/s00134-020-06234-9

61. Hraiech S, Forel JM, Guervilly C, Rambaud R, Lehingue S, Adda M, Sylla P, Valera S, Carvelli J, Gainnier M, Papazian L, Bourenne J (2017) How to reduce cisatracurium consumption in ARDS patients: the TOF-ARDS study. Ann Intensive Care 7:79

62. Tavernier B, Rannou JJ, Vallet B (1998) Peripheral nerve stimulation and clinical assessment for dosing of neuromuscular blocking agents in critically ill patients. Crit Care Med 26:804-805

63. Bouju P, Tadie JM, Barbarot N, Letheulle J, Uhel F, Fillatre P, Grillet G, Goepp A, Le Tulzo Y, Gacouin A (2017) Clinical assessment and train-of-four measurements in critically ill patients treated with recommended doses of cisatracurium or atracurium for neuromuscular blockade: a prospective descriptive study. Ann Intensive Care 7:10

64. Sauder P, Andreoletti M, Cambonie G, Capellier G, Feissel M, Gall O, Goldran-Toledano D, Kierzek G, Mateo J, Mentec H, Mion G, Rigaud JP, Seguin P (2008) Sedation and analgesia in intensive care (with the exception of new-born babies). French society of anesthesia and resuscitation. French-speaking resuscitation society. Ann Fr Anesth Reanim 27:541-551
65. Brull SJ, Kopman AF (2017) Current status of neuromuscular reversal and monitoring: challenges and opportunities. Anesthesiology 126:173-190

66. Pappal RD, Roberts BW, Winkler W, Yaegar LH, Stephens RJ, Fuller BM (2020) Awareness and bispectral index (BIS) monitoring in mechanically ventilated patients in the emergency department and intensive care unit: a systematic review protocol. BMJ Open 10:e034673

67. Poole BR, Reese ZA, Dechen T, Tocci N, Elsamadisi P, Holland S, Hayes MM, Stevens JP (2020) Patient and care delivery characteristics associated with harm from neuromuscular blockade. Crit Care Explor 2:e0147

68. Bass S, Vance ML, Reddy A, Bauer SR, Roach E, Torbic H, Welch S, Duggal A (2019) Bispectral index for titrating sedation in ARDS patients during neuromuscular blockade. Am J Crit Care 28:377-384

69. Karamchandani K, Rewari V, Trikha A, Batra RK (2010) Bispectral index correlates well with Richmond agitation sedation scale in mechanically ventilated critically ill patients. J Anesth 24:394-398

70. Herridge MS, Moss M, Hough CL, Hopkins RO, Rice TW, Bienvenu OJ, Azoulay E (2016) Recovery and outcomes after the acute respiratory distress syndrome (ARDS) in patients and their family caregivers. Intensive Care Med 42:725-738

71. Messner M, Beese U, Romstock J, Dinkel M, Tschaikowsky K (2003) The bispectral index declines during neuromuscular block in fully awake persons. Anesth Analg 97:488-491

72. Schuller PJ, Newell S, Strickland PA, Barry JJ (2015) Response of bispectral index to neuromuscular block in awake volunteers. Br J Anaesth 115(Suppl 1):i95-i103

73. Gainnier M, Roch A, Forel JM, Thirion X, Arnal JM, Donati S, Papazian L (2004) Effect of neuromuscular blocking agents on gas exchange in patients presenting with acute respiratory distress syndrome. Crit Care Med 32:113-119

74. Lyu G, Wang X, Jiang W, Cai T, Zhang Y (2014) Clinical study of early use of neuromuscular blocking agents in patients with severe sepsis and acute respiratory distress syndrome. Zhonghua Wei Zhong Bing Ji Jiu Yi Xue 26:325-329

75. Rao ZL, Yan M (2016) To retain spontaneous breathing or eliminate spontaneous breathing with neuromuscular blockers in acute respiratory distress syndrome patients? Zhonghua Wei Zhong Bing Ji Jiu Yi Xue 28:973-977

76. Slutsky AS, Villar J (2019) Early paralytic agents for ARDS? Yes, no, and sometimes. N Engl J Med 380:2061-2063

77. Papazian L, Hraiech S, Cazenave L, Forel JM (2019) Neuromuscular blocking agents as part of lung-protective strategy in severe ARDS patients. Anaesth Crit Care Pain Med 38:311-313

78. Torbic H, Duggal A (2019) Neuromuscular blocking agents for acute respiratory distress syndrome. J Crit Care 49:179-184

79. Yoshida T, Kavanagh BP, Brochard L (2019) Early neuromuscular blockade in the acute respiratory distress syndrome. N Engl J Med 381:786-787

80. Brower RG, Lanken PN, MacIntyre N, Matthay MA, Morris A, Ancukiewicz M, Schoenfeld D, Thompson BT (2004) Higher versus lower positive end-expiratory pressures in patients with the acute respiratory distress syndrome. N Engl J Med 351:327-336

81. Brower RG, Matthay MA, Morris A, Schoenfeld D, Thompson BT, Wheeler A (2000) Ventilation with lower tidal volumes as compared with traditional tidal volumes for acute lung injury and the acute respiratory distress syndrome. N Engl J Med 342:1301-1308

82. Cavalcanti AB, Suzumura EA, Laranjeira LN, Paisani DM, Damiani LP, Guimaraes HP, Romano ER, Regenga MM, Taniguchi LNT, Teixeira C, Pinheiro de Oliveira R, Machado FR, Diaz-Quijano FA, Filho MSA, Maia IS, Caser EB, Filho WO, Borges MC, Martins PA, Matsui M, Ospina-Tascon GA, Giancursi TS, Giraldo-Ramirez ND, Vieira SRR, Assef M, Hasan MS, Szczeklik W, Rios F, Amato MBP, Berwanger O, Ribeiro de Carvalho CR (2017) Effect of lung recruitment and titrated positive end-expiratory pressure (PEEP) vs. low PEEP on mortality in patients with acute respiratory distress syndrome: a randomized clinical trial. JAMA 318:1335-1345

83. Chang W, Sun Q, Peng F, Xie J, Qiu H, Yang Y (2020) Validation of neuromuscular blocking agent use in acute respiratory distress syndrome: a meta-analysis of randomized trials. Crit Care 24:54

84. Hua Y, Ou X, Li Q, ZhuT (2020) Neuromuscular blockers in the acute respiratory distress syndrome: a meta-analysis. PLOS ONE 15:e0227664

85. Wei XB, Wang ZH, Liao XL, Guo WX, Qin TH, Wang SH (2019) Role of neuromuscular blocking agents in acute respiratory distress syndrome: an 
updated meta-analysis of randomized controlled trials. Front Pharmacol 10:1637

86. Zheng Z, Jiang L, Zhang S, Guervilly C, Zhang M, Feng X, Ding J (2020) Neuromuscular blocking agents for acute respiratory distress syndrome: an updated meta-analysis of randomized controlled trials. Respir Res $21: 23$

87. Jonkman AH, de Vries HJ, Heunks LMA (2020) Physiology of the respiratory drive in ICU patients: implications for diagnosis and treatment. Crit Care 24:104

88. Vaporidi K, Akoumianaki E, Telias I, Goligher EC, Brochard L, Georgopoulos D (2020) Respiratory drive in critically III patients. Pathophysiology and clinical implications. Am J Respir Crit Care Med 201:20-32

89. Brochard L, Slutsky A, Pesenti A (2017) Mechanical ventilation to minimize progression of lung injury in acute respiratory failure. Am J Respir Crit Care Med 195:438-442

90. Hooijman PE, Beishuizen A, Witt CC, de Waard MC, Girbes AR, Spoelstrade Man AM, Niessen HW, Manders E, van Hees HW, van den Brom CE, Silderhuis V, Lawlor MW, Labeit S, Stienen GJ, Hartemink KJ, Paul MA, Heunks LM, Ottenheijm CA (2015) Diaphragm muscle fiber weakness and ubiquitin-proteasome activation in critically ill patients. Am J Respir Crit Care Med 191:1126-1138

91. Goligher EC, Fan E, Herridge MS, Murray A, Vorona S, Brace D, Rittayamai N, Lanys A, Tomlinson G, Singh JM, Bolz SS, Rubenfeld GD, Kavanagh BP, Brochard LJ, Ferguson ND (2015) Evolution of diaphragm thickness during mechanical ventilation. impact of inspiratory effort. Am J Respir Crit Care Med 192:1080-1088

92. Levine S, Nguyen T, Taylor N, Friscia ME, Budak MT, Rothenberg P, Zhu J, Sachdeva R, Sonnad S, Kaiser LR, Rubinstein NA, Powers SK, Shrager JB
(2008) Rapid disuse atrophy of diaphragm fibers in mechanically ventilated humans. N Engl J Med 358:1327-1335

93. Campbell EJ, Gandevia SC, Killian KJ, Mahutte CK, Rigg JR (1980) Changes in the perception of inspiratory resistive loads during partial curarization. J Physiol 309:93-100

94. Doorduin J, Nollet JL, Roesthuis LH, van Hees HW, Brochard LJ, Sinderby CA, van der Hoeven JG, Heunks LM (2017) partial neuromuscular blockade during partial ventilatory support in sedated patients with high tidal volumes. Am J Respir Crit Care Med 195:1033-1042

95. Papazian L, Aubron C, Brochard L, Chiche JD, Combes A, Dreyfuss D, Forel JM, Guerin C, Jaber S, Mekontso-Dessap A, Mercat A, Richard JC, Roux D, Vieillard-Baron A, Faure H (2019) Formal guidelines: management of acute respiratory distress syndrome. Ann Intensive Care 9:69

96. Guerin C, Reignier J, Richard JC, Beuret P, Gacouin A, Boulain T, Mercier E, Badet M, Mercat A, Baudin O, Clavel M, Chatellier D, Jaber S, Rosselli S, Mancebo J, Sirodot M, Hilbert G, Bengler C, Richecoeur J, Gainnier M, Bayle F, Bourdin G, Leray V, Girard R, Baboi L, Ayzac L, Group PS (2013) Prone positioning in severe acute respiratory distress syndrome. N Engl J Med 368:2159-2168

97. Alhazzani W, Belley-Cote E, Møller MH, Angus DC, Papazian L, Arabi YM, Citerio G, Connolly B, Denehy L, Fox-Robichaud A, Hough CL, Laake $J$ H, Machado FR, Ostermann M, Piraino T, Sharif S, Szczeklik W, Young PJ, Gouskos A, Kiedrowski K, Burns KE (2020) Neuromuscular blockade in patients with ARDS: a rapid practice guideline. Intensive Care Med 46:1977-1986 